\title{
Changes in ATP Concentration in Escherichia coli during Induction of the SOS System by Mitomycin C and Bleomycin
}

\author{
By RICARDO GUERRERO, * MONTSERRAT LLAGOSTERA, \\ ANTONIO VILLAVERDE AND JORGE BARBÉ \\ Department of Microbiology and Institute for Fundamental Biology, Autonomous University of \\ Barcelona, Bellaterra (Barcelona), Spain
}

(Received 13 February 1984)

\begin{abstract}
Treatment of Escherichia coli with bleomycin induced a dramatic increase in ATP concentration in the first $30 \mathrm{~min}$. Afterwards, in RecA ${ }^{+}$strains, ATP dropped quickly to values similar to those of untreated cells. Mutants of $E$. coli defective in either RecA protein or RecA protease activity did not show this decrease, indicating that it was due to the action of RecA protease. The increase in ATP in the first 30 min was dependent on RecBC exonuclease activity and must have been due to substrate level phosphorylation, since an uncoupler such as dinitrophenol did not affect it. Nevertheless, mitomycin $\mathrm{C}$ did not induce any change in ATP pools of Rec $\mathrm{A}^{+}$ strains, at least during 120 min following treatment. The implications of these findings are discussed in relation to the possible pathways of activation of RecA protease.
\end{abstract}

\section{INTRODUCTION}

The rec $A$ and lexA genes play major roles in induced responses (SOS system) of cells that suffer damage to their DNA (Witkin, 1976). This response is also dependent on ssb genes and includes mutagenesis, filamentation, inhibition of cell respiration, prophage induction and amplification of RecA protein (for a review see Little \& Mount, 1982). Expression of the SOS system is not an all-or-none process, since some SOS functions may be induced by some treatments but not by others (Guerrero \& Barbé, 1982; Barbé et al., 1983a). The lex $A$ gene product is a repressor of the rec $A$ and $l e x A$ genes (Brent \& Ptashne, 1981; Little et al., 1981) as well as of several SOS genes which specify the functions cited above. Little \& Mount (1982) have presented a model for the regulation of the SOS response: the $\operatorname{rec} A$ gene product is activated by some signal such as singlestrand DNA fragments generated by DNA damage, and acquires proteolytic properties enabling it to cleave the LexA protein repressing the $\operatorname{rec} A$ gene. This derepression leads to the formation of large amounts of RecA protein, which upon activation cleaves the LexA proteins repressing the target genes and causes the induced systems to become functional. In a surviving cell, DNA repair decreases generation of the signal for activation of the RecA protein so that the protease level decreases, repressors accumulate, and all induced genes become repressed.

We have shown (Barbé et al., 1983b) that in Escherichia coli UV irradiation induces a twofold increase in the ATP concentration in the first $20 \mathrm{~min}$, which is dependent on RecBC exonuclease activity and is due to substrate level phosphorylation. Furthermore, in RecA ${ }^{+}$ strains the ATP concentration drops quickly below values of non-irradiated cells. This decrease in ATP must be attributed to cleavage of LexA repressor by RecA protease because it is not shown by mutants of $E$. coli defective in RecA protein or with either RecA protease activity deficient or protease resistant LexA repressor. Nevertheless, production of cellular ATP after induction of the SOS system by continuous treatment with chemical agents such as bleomycin and mitomycin $\mathrm{C}$ has not, to our knowledge, been reported. For this reason, we have performed the present study, and we have found that bleomycin gives rise to the same behaviour as UV 


\section{Table 1. Strains of Escherichia coli used}

\begin{tabular}{lll} 
Strain & \multicolumn{1}{c}{ Genotype } & \multicolumn{1}{c}{ Source or reference } \\
AB1157 & argE3 his4 thrl proA2 leu6 thil supE44 rpsL & Howard-Flanders \& Theriot (1962) \\
AB2467 & As AB1157, recA13 & Howard-Flanders \& Theriot (1966) \\
IC 41 & As AB1157, recA430 & M. Blanco* \\
IC 53 & As AB1157, recB21 recC22 & M. Blanco*
\end{tabular}

*M. Blanco, Instituto de Investigaciones Citológicas, Amadeo de Saboya 4, Valencia 10, Spain.

irradiation, whereas mitomycin C does not produce any change in the ATP concentration of $\mathrm{RecA}^{+}$strains. The possible causes and implications of these results are discussed.

\section{METHODS}

Bacteria, growth conditions and mutagenic treatment. Bacterial strains used in this work are listed in Table 1. They are all $E$. coli $\mathrm{K} 12$ derivatives. Cultures were grown with shaking to $2 \times 10^{8}$ cells $\mathrm{ml}^{-1}$ in LB medium (Miller, 1972): at this point, bleomycin or mitomycin $\mathrm{C}$ was added and incubation was continued at $37^{\circ} \mathrm{C}$.

Determination of cell size. Cell size was determined with a Coulter counter model ZBI equipped with a $30 \mu \mathrm{m}$ orifice. An attenuation setting of 1 , aperture current setting of $\frac{1}{\xi}$ and a lower threshold of 5 were used for all counts. Periodically, culture samples of $0.5 \mathrm{ml}$ were added to $25 \mathrm{ml}$ of filtered Isoton II (Coultronics). These samples had been previously diluted in physiological Ringer solution to keep the particle counts between 7000 and 50000 per $50 \mu 1$.

Determination of intracellular ATP concentration. After bleomycin, mitomycin C and/or dinitrophenol addition, culture samples of $1 \mathrm{ml}$ were added to $4 \mathrm{ml} 0.025 \mathrm{M}$-Tris/ $/ \mathrm{HCl}$ buffer (pH 7.75) and boiled in a water bath for $5 \mathrm{~min}$; the suspension was centrifuged for $10 \mathrm{~min}$ at $4{ }^{\circ} \mathrm{C}$ and $8000 \mathrm{~g}$. ATP present in the supernatant was immediately measured by the firefly luciferin-luciferase assay (Chapman et al., 1971).

Chemicals. Mitomycin C was obtained from Sigma and bleomycin from Almirall Laboratories (Barcelona, Spain): dinitrophenol and mineral salts were from Merck; and tryptone, yeast extract and agar were from Oxoid.

\section{RESULTS}

The response of intracellular ATP concentration in $\mathrm{RecA}^{+}$strains of $E$. coli after bleomycin or mitomycin $C$ treatment is shown in Fig. 1. Under these conditions, during the first $30 \mathrm{~min}$ an increase occurred in the ATP concentration of $\operatorname{Rec} \mathrm{A}^{+}$cells treated with bleomycin. Afterwards, the ATP concentration dropped to values similar to those of untreated cells. In contrast, RecA ${ }^{+}$ cells treated with mitomycin C showed no change in ATP concentration up to 120 min after addition of the compound. However, the rec $A$-dependent inhibition of cell division had already been induced by mitomycin $\mathrm{C}$ between 20 and $30 \mathrm{~min}$ after the addition of the chemical (Fig. 2).

This behaviour of the ATP concentration during mitomycin $C$ treatment could be explained if, in these conditions, the cells had an equilibrium between ATP production by substrate level phosphorylation (Barbé et al., 1983b) and ATP degradation as a consequence of the activity of RecA protein. To test this possibility, we studied changes in ATP concentration in recAl3 (RecA defective protein), rec $A 430$ (RecA protease activity defective) and $r e c B / C$ (exonuclease $\mathrm{V}$ defective) mutants following the addition of bleomycin or mitomycin $C$. Figure 3 shows that although both recA430 and recAl3 mutants showed an increase in the concentration of ATP after bleomycin treatment, neither (unlike the $\operatorname{Rec} A^{+}$strain) showed the post-30 min fall (Fig. 1). Figure 3 also shows that the increase in ATP concentration induced by bleomycin was dependent on $\mathrm{rec} B / C$ activity, as it was in the case of UV irradiation (Barbe et al., 1983b).

In contrast with these results, $\operatorname{rec} A 13, \operatorname{rec} A 430$ and $\operatorname{rec} B / C$ strains did not show any variation in ATP concentration during $50 \mathrm{~min}$ after addition of mitomycin $C$ (Fig. 4). Nevertheless, between 50 and 60 min following treatment with this compound there was an increase in ATP concentration in both recA13 and recA430 mutants and a decrease in the ATP concentration of the $\operatorname{rec} B / C$ mutant. These results suggest that the constant intracellular concentration of ATP in a $\operatorname{Rec}^{+}$strain following mitomycin $\mathrm{C}$ shock has two different origins: during the first $50 \mathrm{~min}$ it should be independent of $\operatorname{rec} A$ and $\operatorname{rec} B / C$ activity, whereas from this time on it should be dependent on the function of both genes.

We previously suggested that the increased ATP concentration following UV irradiation 


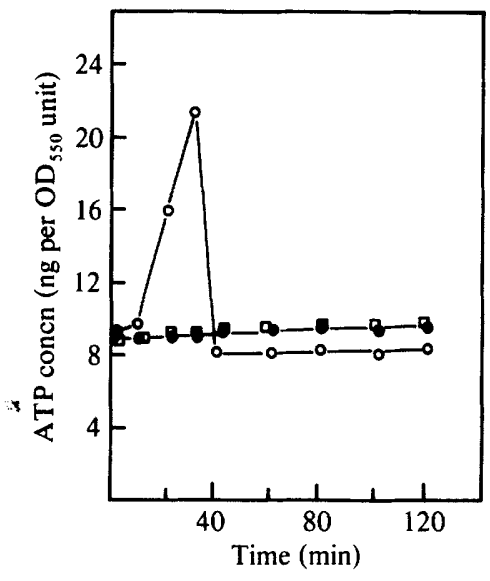

Fig. 1

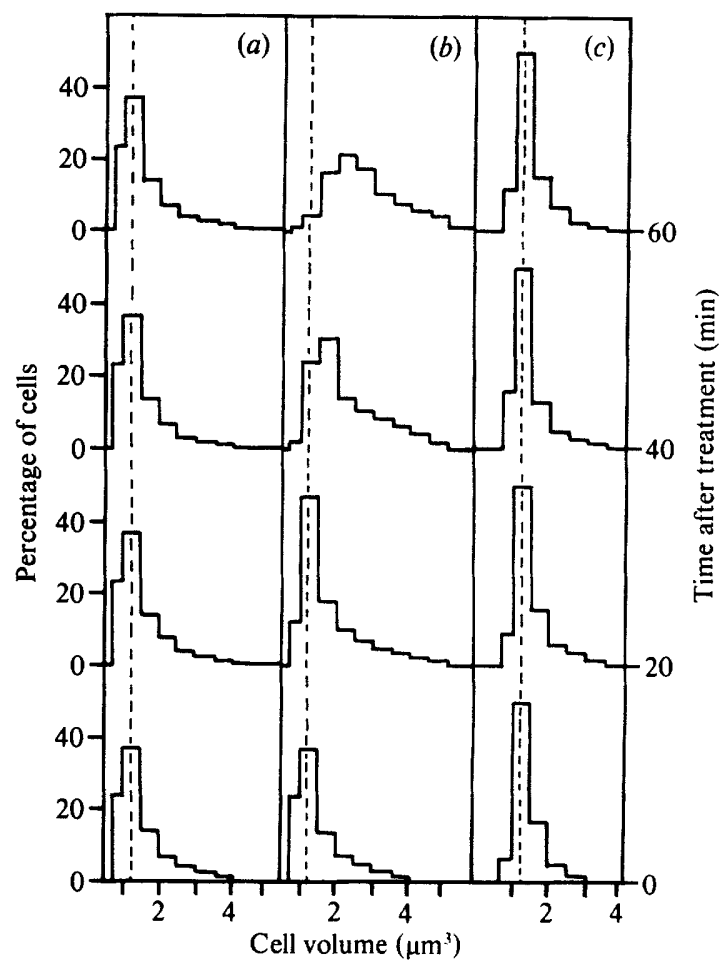

Fig. 2

Fig. 1. Response of ATP concentration in a $\operatorname{RecA}^{+}$strain of $E$. coli after addition of bleomycin $(O)$ at $20 \mu \mathrm{g} \mathrm{ml}^{-1}$ and mitomycin $\mathrm{C}(\odot)$ at $40 \mu \mathrm{g} \mathrm{ml}^{-1}$. The ATP concentration of an untreated culture $(\square)$ is shown as a control.

Fig. 2. Effect of mitomycin $C\left(40 \mu \mathrm{g} \mathrm{m}^{-1}\right)$ on cell volume of $\operatorname{RecA}^{+}$and $\operatorname{Rec} \mathrm{A}^{-}$strains of E. coli.

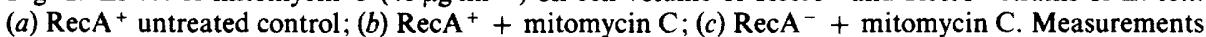
were made at intervals after the treatment.

must be attributed to substrate level phosphorylation (Barbe et al., 1983b). To determine the origin of ATP following mitomycin C and bleomycin treatments, we studied the effect on the ATP concentration of the uncoupler dinitrophenol (DNP). Figure 5 shows that DNP had no effect on the concentration of ATP in RecA ${ }^{+}$cells treated with bleomycin. Furthermore, in the first $50 \mathrm{~min}$ a $\mathrm{RecA}^{+}$culture, growing in the presence of $250 \mu \mathrm{M}$-DNP, when treated with mitomycin C had the same concentration of ATP as an untreated control culture (Fig. 6). Subsequently, the ATP concentration in cells to which mitomycin $C$ had been added became higher than that in untreated cells. This fact suggests that, $50 \mathrm{~min}$ after the addition of mitomycin C, a fraction of the ATP present in the cells must be attributed to substrate level phosphorylation.

\section{DISCUSSION}

These results indicate that, like UV irradiation, bleomycin gives rise to a $\operatorname{rec} B / C$-dependent increase in ATP concentration during the first $30 \mathrm{~min}$ after addition. Beyond this point, the concentration drops quickly to that of untreated cells in a $\operatorname{RecA}^{+}$strain. Nevertheless, mitomycin $\mathrm{C}$ did not induce any change in ATP concentration in $\mathrm{Rec} \mathrm{A}^{+}$cells, at least for $120 \mathrm{~min}$. Furthermore, in rec $A 13$ and rec $A 430$ mutants, mitomycin $C$ produced an increase in ATP concentration after $50 \mathrm{~min}$, whereas in a $\mathrm{rec} B / C$ mutant the ATP concentration began to fall at this time. Data obtained with these three mutants suggest that in the presence of mitomycin C, during the first $50 \mathrm{~min}$ RecA protein does not need ATP to induce SOS functions. The response to bleomycin (Figs 1 and 3) and UV irradiation (Barbé et al., 1983b) is different. 


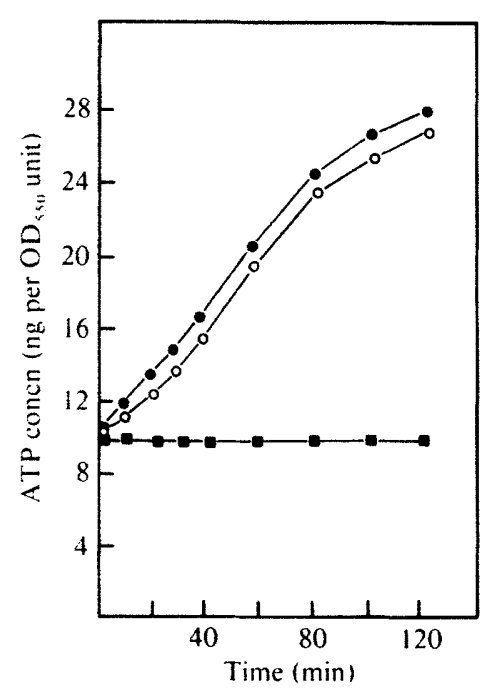

Fig. 3

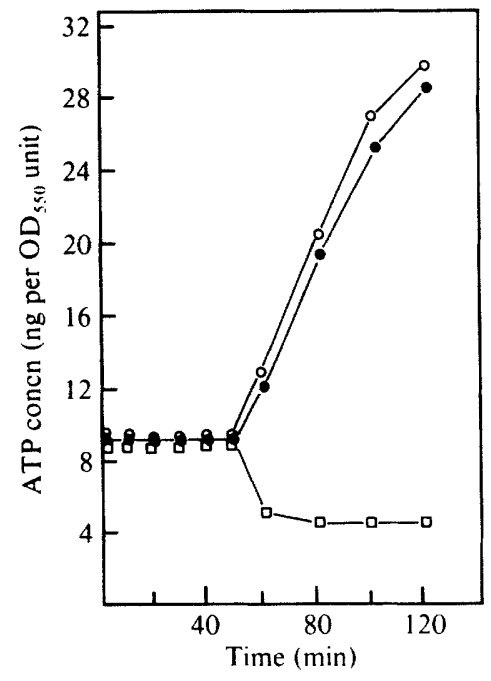

Fig. 4

Fig. 3. Response of ATP concentration in $\operatorname{rec} A 13(O), \operatorname{rec} A 430(O)$ and $\operatorname{rec} B 21$ recC22( $\square)$ mutants of E. coli after addition of bleomycin at $20 \mu \mathrm{g} \mathrm{ml}^{-1}$.

Fig. 4. Response of ATP concentration in recA13(O), rec A430 (O) and recB2l recC22( $\square)$ mutants of E. coli after addition of mitomycin $C$ at $40 \mu \mathrm{g} \mathrm{m}^{-1}$.

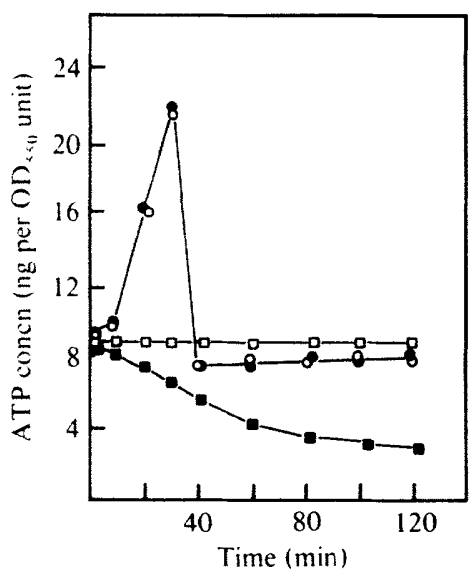

Fig. 5

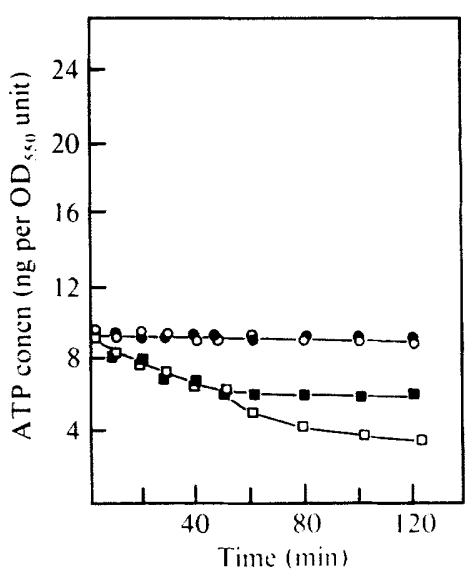

Fig. 6

Fig. 5. Effect of the uncoupler dinitrophenol at $250 \mu \mathrm{M}$ on the cellular ATP concentration of a RecA * strain of $E$. coli after treatment with bleomycin at $20 \mu \mathrm{g} \mathrm{ml}^{-1}\left(O^{\prime}\right)$. Dinitrophenol and bleomycin were simultaneously added. The ATP concentrations of three cultures treated only with either bleomycin (O) or dinitrophenol ( $\square$ ), as well as without any compound $(\square)$, are shown as controls.

Fig. 6. Effect of the uncoupler dinitrophenol at $250 \mu \mathrm{M}$ on the cellular ATP concentration of a RecA ${ }^{+}$ strain of $E$. coli after treatment with mitomycin $C$ at $40 \mu \mathrm{g} \mathrm{ml}^{-1}$ ( $\square$ ). Dinitrophenol and mitomycin $C$ were simultaneously added. The ATP concentrations of three cultures treated only with either mitomycin $\mathrm{C}(O)$ or dinitrophenol $(\square)$, as well as without any compound $(O)$, are shown as controls. 
After 50 min a constant concentration of ATP is maintained because the ATP hydrolysed by the RecA protein is regenerated by metabolism of DNA degradation products, caused by the RecBC exonuclease (Fig. 4), through both oxidative (Barbé et al., 1983c) and substrate level phosphorylation (Fig. 6). In this context, an interesting point is why some SOS functions such as filamentation may be expressed following mitomycin $\mathrm{C}$ treatment (Fig. 2) without $\operatorname{rec} A$ dependent ATP hydrolysis (Fig. 3). A possible explanation of this situation may be found in the kind of lesion caused by mitomycin $C$. Thus, this compound would be able to generate damage in the DNA which activates the RecA protein without the help of any cofactor such as ATP. Casaregola et al. (1982) have shown that mitomycin C does not need an active replication fork to induce massive synthesis of RecA protein. Furthermore, ATP- $\gamma-\mathrm{S}$ is not hydrolysed efficiently during $\lambda$ repressor cleavage in vitro, though it can support a much higher cleavage rate than does ATP in the same reaction (Craig \& Roberts, 1981). This last result suggests that RecA protein does not always require hydrolysis of ATP to support protease activity. However, after expression of SOS functions, specific lesions produced by mitomycin $\mathrm{C}$ would be repaired and, in consequence, some fragments of DNA might be generated by exonuclease V degradation. Afterwards, these fragments could be used to produce ATP by substrate level phosphorylation.

The observation that both recAl3 (recombination defective) and recA430 (recombination proficient) mutants show an increase in ATP concentration 50 min after mitomycin $C$ addition, suggests that during this time ATP hydrolysis takes place which is dependent on rec $A$-protease activity, but not on a recombination process. This situation could be attributed to two factors. One would be that some molecules of the RecA protease population use ATP as a cofactor, despite the presence of mitomycin $C$. The second would be that after approximately $50 \mathrm{~min}$, there is the expression of some recA-dependent activity which could require ATP hydrolysis. Further investigations will be necessary to clarify this particular aspect of SOS system induction by mitomycin $\mathrm{C}$.

We thank Dr M. Blanco for his generous gift of several strains. We acknowledge the help of the Comisió Interdepartamental de Recerca i Innovació Tecnologica of the Generalitat de Catalunya for a grant for the purchase of equipment. This work was partially supported by a grant of the Comisión Asesora de Investigación Científica y Técnica, Spain.

\section{REFERENCES}

Barbé, J., Vericat, J. A. \& Guerrero, R. (1983a). Discriminated induction of SOS functions in Escherichia coli by alkylating agents. Journal of General Microbiology 129, 2079-2089.

Barbé, J., Villaverde, A. \& Guerrero, R. (1983b). Evolution of cellular ATP concentration after UVmediated induction of SOS system in Escherichia coli. Biochemical and Biophysical Research Communications 117, 556-561.

Barbé, J., Vericat, J. A. \& Guerrero, R. (1983c). rec $A$-Dependent inhibition of cell respiration is not induced by mitomycin C in Escherichia coli. Mutation Research 120, 1-5.

Brent, R. \& Ptashne, M. (1981). Mechanism of action of the lexA gene product. Proceedings of the National Academy of Sciences of the United States of America 78, $3700-3704$.

Casaregola, S., D’ari, R. \& Huisman, O. (1982). Role of DNA replication in the induction and turnoff of the SOS response in Escherichia coli. Molecular and General Genetics 185, 440-444.

Chapman, A. G., Fall, L. \& Atkinson, D. E. (1971). Adenylate charge in Escherichia coli during growth and starvation. Journal of Bacteriology 108, 1072 1086.

Craig, N. L. \& Roberts, J. W. (1981). Function of nucleoside triphosphate and polynucleotide in Escherichia coli recA protein-directed cleavage of phage $\lambda$ repressor. Journal of Biological Chemistry. 256, 8039-8044.

Guerrero, R. \& Barbé, J. (1982). Expression of recAgene dependent SOS functions in Salmonella typhimurium. Antonie van Leeuwenhoek 48, 159-167.

HOWARD-Flanders, P. \& THERIOT, L. (1962). A method for selecting radiation sensitive mutants of Escherichia coli. Genetics 47, 1219-1224.

Howard-Flanders, P. \& Theriot, L. (1966). Mutants of Escherichia coli $\mathrm{K} 12$ defective in DNA repair and in genetic recombination. Genetics 53, 1137-1150.

LitTle, J. W. \& Mount, D. W. (1982). The SOS regulatory system of Escherichia coli. Cell 29, 11-22. Little, J. W., Mount, D. W. \& Yanisch-Perron, C. R. (1981). Purified lexA protein is a repressor of the rec $A$ and lex $A$ genes. Proceedings of the National Academy of Sciences of the United States of America 78, 4199-4203.

Miller, J. H. (1972). Experiments in Molecular Genetics. New York: Cold Spring Harbor Laboratory.

WITKIN, E. M. (1976). Ultraviolet mutagenesis and inducible DNA repair in Escherichia coli. Bacteriological Retien's 40, 869-907. 